\title{
THE TYPE FETISH
}

\author{
By J. R. DE LA TORRE-BuENO \\ White Plains, N. Y.
}

Professor Embrik Strand writes in Psyche, for September, 1929, an extremely thought-provoking article under the title "Down with the Type Cult"1, which I translate as in my heading. Whether our personal opinions run with his or not, we must admit he discusses what is becoming an extremely serious matter in entomology. We have types ranging from dipteran ovaries to fragmentary parts of insects, microscopic mounts, and, of course, the whole insect. These are scattered to the four quarters of the globe, in museums and in private collections. In many instances, internal evidence may point to certain specimens or to a series of specimens with which the author worked, but nothing on the specimens themselves shows that these were the ones from which the description is drawn up. Again, we face the condition that a type label may have been carelessly lost or put on a wrong specimen; or even removed or changed of set purpose.

Dr. Strand's idea of doing away with type specimens is not novel. Over twenty years ago, Dr. Verrill, the English dipterist, advocated the destruction of all types and the rejection of all descriptions unintelligible without the type. I have always maintained that paper and ink are far more lasting than specimens; and while we today may have the use of the type material of our contemporaries, it does not follow that our successors will. And even where types are extant, it is difficult to have access to them: Institutions are justly averse to lending types, particularly when these types have far to travel to the borrower. The vicissitudes of a type start when it is taken out of its case and continue

${ }^{1}$ Vol. XXXVI, pp. $228-231$. 
until it is safely back, perhaps not so entire as when it started, in spite of all the care exercised by both lender and borrower. Who has not at some time received a small box with one or more pins careering madly about in a debris of insect fragments? The policy of institutions is becoming more and more crystallized against the lending of types; and it is necessary now in many instances to inspect types in the parent collection itself, and to have to travel long distances in order to do so.

Another consequence flowing from the type cult is that certain describers content themselves with a one- or twoline, so-called, description; and blandly refer other students to the extant type or types. This saves the describer great labor: vice-versa the student.

Of course, these conditions present a full field to the synonym-hounds, who are thus enabled to cast what they please into the discard; or to erect new species on insufficient grounds.

Yet, in view of the extreme parsimony of words of many of the older descriptions and of their authors, what could we do without their types (if extant)?

Figures are sometimes advocated to take the place of types, or to make reference to them unnecessary. But who is to guarantee the accuracy of any figure? If an author makes the drawing, he may not be adept enough to bring out the particular features of the insect which form its basic characteristics (and many of these are impossible to depict in words or in drawing, because they are a part of the habitus or facies of the insect, elusive and difficult to seize upon). Two men may have straight noses, yet each has some fleeting characteristic which differentiates them. Every artist gives these characteristics a personal and probably subjective bent as he protrays them. Uncle Sam as portrayed by an American has an entirely different cast of countenance from the same portrayal by a Japanese, or by a German, or by a Russian, or even by an Englishman. And this is the personal equation of the artist! But when it comes to some other person, no matter how capable, imperceptible (and sometimes obvious) differences creep in. This has happened time and again; and any entomologist may cite numerous instances of these subtle differences, 
culled from his own experience. Photography is also suggested as a solution. But photography requires great expertness to attain results. And even here, the very direction of the light may obscure the most important characteristics. The reproduction of the most careful and accurate photograph is also fraught with hazard. Not long since, an entomologist friend of mine had a plate made from a photograph of the venation of an odonate wing. Here is an object all in the same plane, all in lines, possible to photograph exactly, and not depending on light and shade for its accuracy. Yet, the engraver perfected the photograph by adding a line where he thought it was needed, thus creating not only a new species, but a new genus as well! And after this come the hazards of proper printing.

All these considerations lead inescapably to the description as the residual sine qua non, Dr. Strand's fundamental position as I understand it.

When we arrive at this point, we arrive at the crux of all modern insect taxonomy. The only solution is an adequate description to stand or fall alone, without benefit of types. But what form shall such a description take? Is it to be a taxonomic description, restricted only to selected critical characters? Or is it to be a morphological description taking in each and every structure, internal as well as external? A taxonomic description of Homo sapiens, var entomologus, might occupy a printed page, but volumes would be required for a complete morphological description. And what are we to do about those who make genitalia the beall and end-all of specific description?

A modern description, to be acceptable must be in such form as to stand alone independent of a type or of any other description. And by its form it should not only apply to the species described exclusively, but it should also cut all other cognate forms. This eliminates all ambiguity and makes it impossible for one neighbor to be mistaken for another.

When this is done, the type fetish will be automatically abolished, thus attaining the very laudable desire of Dr. Strand.

Et quis custodiet ipsos custodes? 

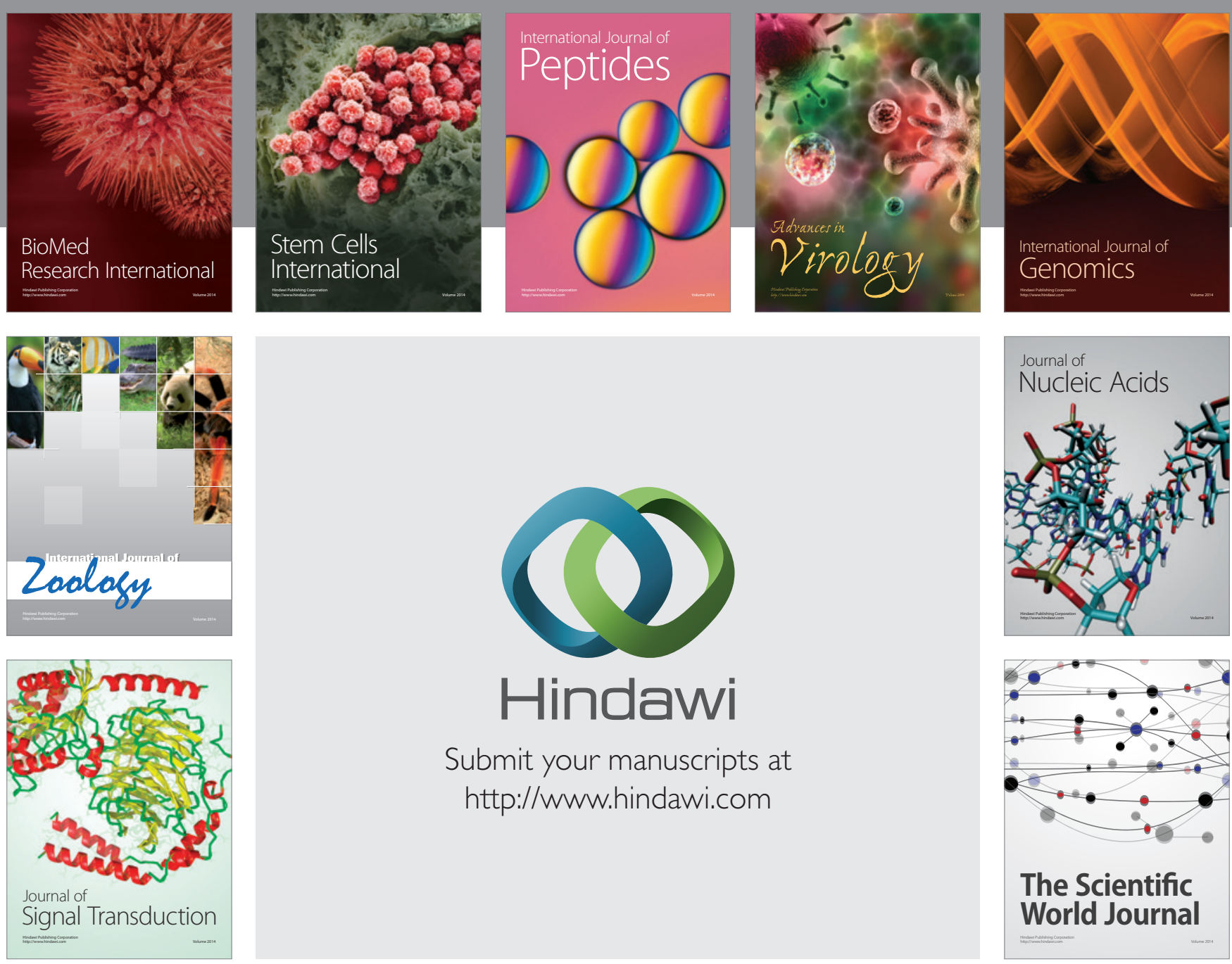

Submit your manuscripts at

http://www.hindawi.com
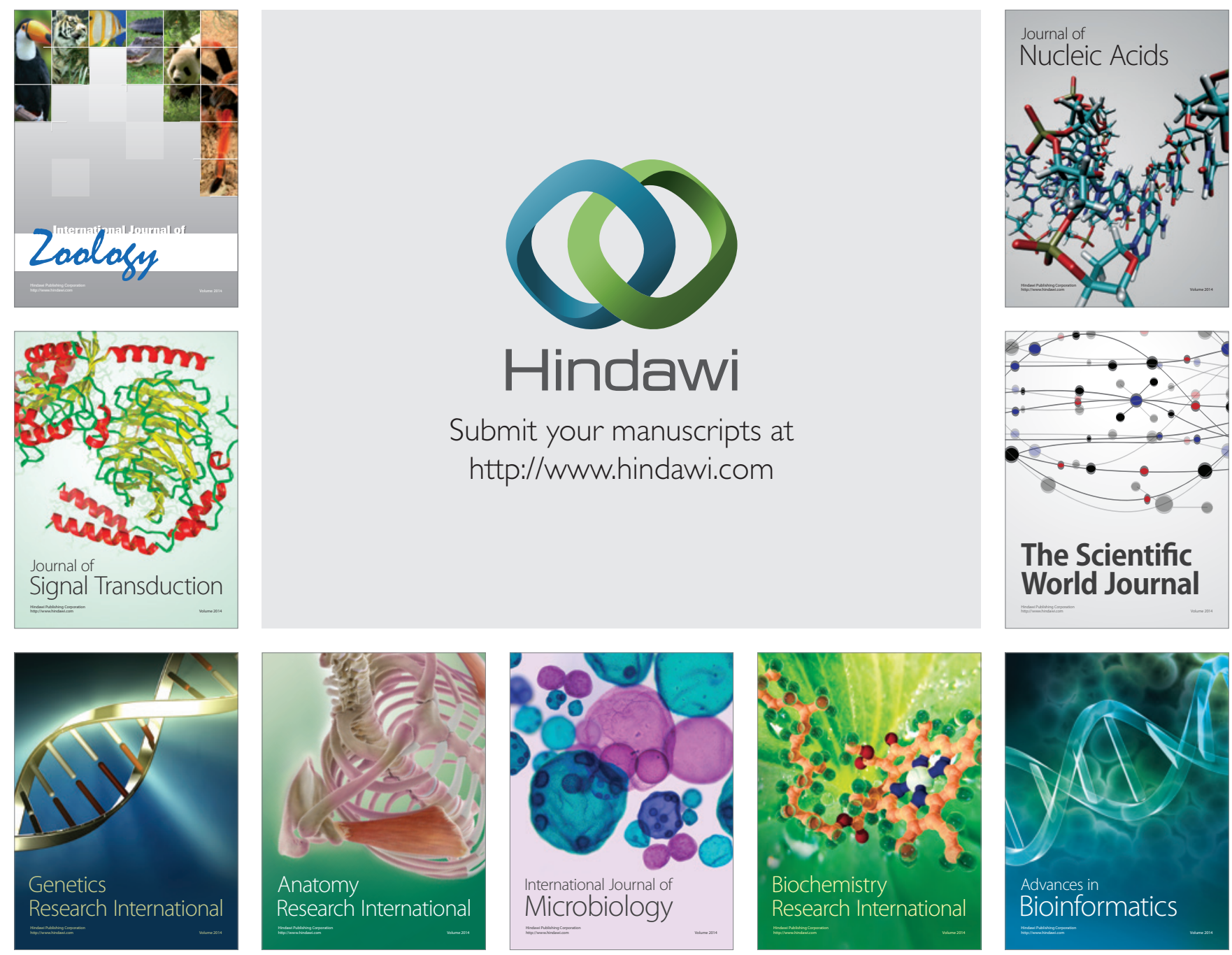

The Scientific World Journal
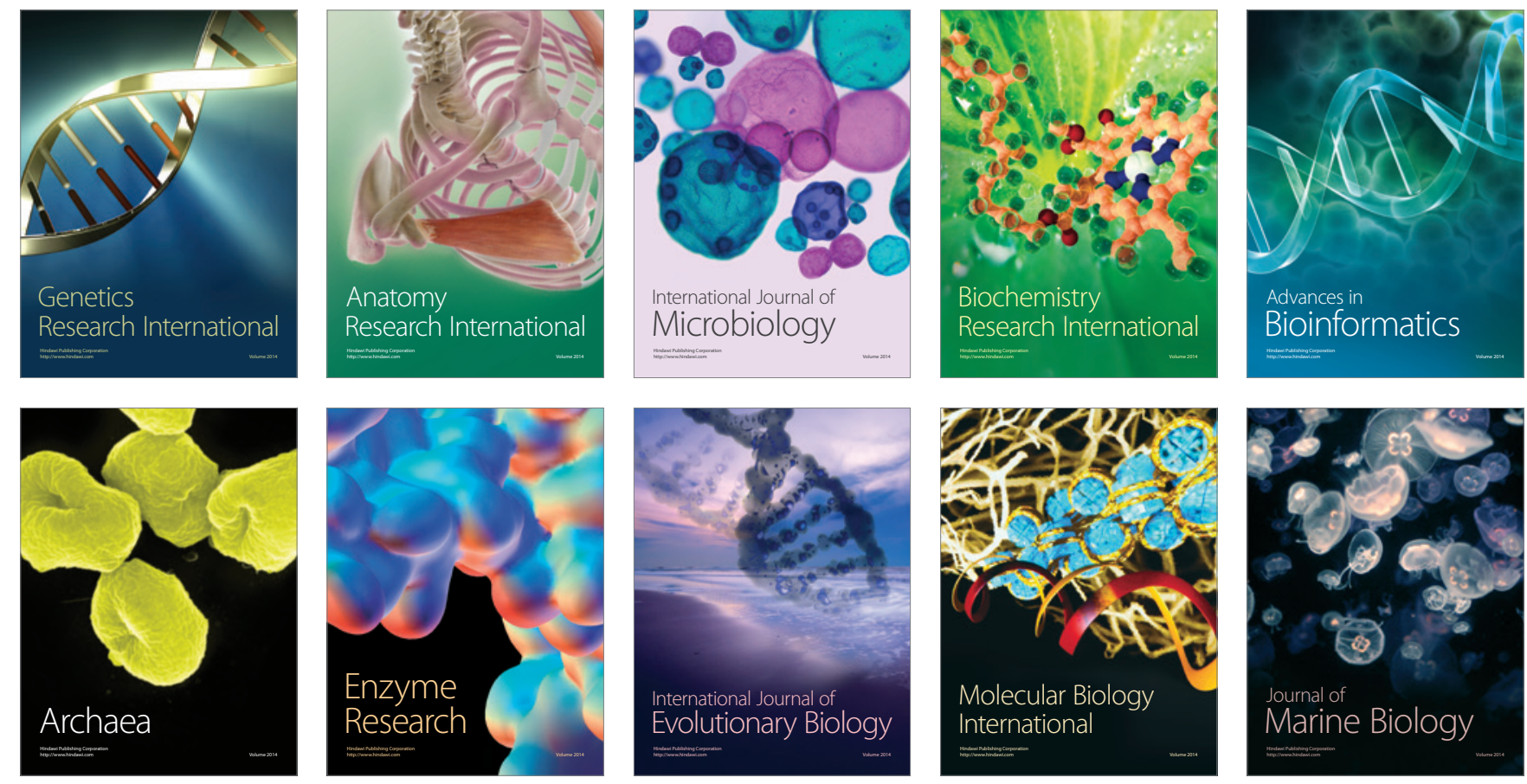